\title{
A UTILIZAÇÃO EM DIREITO ADMINISTRATIVO DAS REGRAS E PRINCÍPIOS DO DIREITO PRIVADO
}

\author{
ANDRÉ HaURIOU \\ Prafeesor na Faculdade de Direito \\ de Toulouse
}

\begin{abstract}
SUMARIO: - Direito privado e direito administrativo - Justiça comutativa e Justiça distributiva - A funçäo supletiva do direito privado - As delegações em direito público e a teoria do mandato.
\end{abstract}

* Quando, na escola de Direito, chegamos ao curso de direito administrativo, somos advertidos, desde as primeiras liçôes, de tratar-se de uma disciplina autônoma, diferente daquelas até então estudadas, e de que convém, para melhor compreensão do seu caráter, esquecermos, se possível, os ensinamentos ministrados nos ramos vizinhos e particularmente em direito privado.

No entanto, quando aprofundamos os problemas de direito administrativo, e sobretudo quando os consideramos com espirito curioso das evoluções históricas, percebemos que grande número de preceitos administrativos, de teorias ou de principios foram tomados do direito privado e muito especialmente do direito civil.

$\mathbf{E}$ são essas utilizações em direito administrativo das regras e princípios do direito privado que queremos ligeiramente examinar.

Mas, para nos inteirarmos das condições em que são feitos êsses empréstimos e do valor dos mesmos, o melhor será, antes de indicar os contactos que se estabelecem, começarmos por mostrar as diferenças que existem entre o direito privado e o direito administrativo.

* Traduzido, por Paulo da Mata Machado, do Recueil d'Efudes mer los Sources du droit en l'homeur de Frangois Geny, tome III, Les sources des diverses branches du droit, Librairie du Recueil Sirey, Paris, 1934, págs. 92-99. 
Direito privado e direito administrativo - Se considerarmos o direito privado $\mathrm{cm}$ seus caracteres e nas suas tendências dominantes, uma primeira verificação se nos imporá : a de que, nesse ramo do direito, não se encontra mais que uma só categoria de sujeitos de direito ou de agentes juridicos, tendo, em princípio, os mesmos direitos.

Com efeito, à parte as exceçõ as tiradas da organização da família, todos os indivíduos têm à sua disposição os mesmos direitos subjetivos e, por outro lado, as pessoas juridicas do direito privado (e particularmente as sociedades comerciais) têm, exceto as incapacidade inerentes à sua natureza de ser imaginário, as mesmas possibilidades e os mesmos direitos que os particulares.

Segunda verificação é a de que os diversos agentes jurídicos estão do mesmo mcdo subo-dinados ao direito objetivo, à legalidade. As regras de direito, em direito privado, aparecem como transcendentes acs sujeitos de direito que elas limitam, isto é, como estabelecidas, mantidas e executadas sem que sôbre eias tenham êles ação (excetuando-se o mecanismo da representação nacional, que năo impede, aliás, que os individuos, isoladamente considerados, fiquem obrigados por leis que êles absolutamente não tinham aprovado prèviamente).

Essas regras transcendentes de direito aplicam-se do mesmo modo a todos os sujeitos de direitos, seja qual fôr seu poder econômico ou pclítico, porque êles têm o mesmo poder jurídico.

S乞 quisermos resumir em uma fórmula a marcha geral do direito privacio, civil ou comercial, poderemos dizer que essas disc;plinas se dedicam a manter a balança igual entre as partes.

Ao contrário, o direito administrativo é uma disciplina que não mantém a balança igual entre as partes.

De um lado, sôbre o plano do direito administrativo, encontramos duas categorias diferentes de partes ou de sujeitos de direitos: os administrados e as diversas pesscras jurídicas administrativas.

Doutro lado, essas duas categorias de agentes jurídicos têm direitos e poderes muito diferentes, seja em suas relações recíprocas, seja em frente às regras de direito.

As administrações públicas possuem, para o cumprimento de sua missāc, diraitos exorbitantes do direito comum, procedentes da idéia de requisição, expropriação, requisição pròpriamente dita, direites de polícia, obras públicas, etc. Muito mais, elas gozam, para exercê-los, de privilégios particulares e muito especialmsnte da prerrogativa de ação própria (prérogative d'action d'office) que 
Thes permite executar as decisóes tomadas sem se preocuparem com o consentimento dos interfssados.

Além disso, em face das regras do direito objetivo, as administrações públicas, na qualidade de agentes jurídicos, exercem uma espécie de dominação, como não podem exercê-la os indivíduos em relação às regras do direito privado, nem, com mais forte razão, os administrados em relação às regras do direito administrativo.

Sem dúvida, essa superioridade não é muito visível quando se trata de preceitos legais, embora tenha a administração laços muito estreitos com o govêrno e exerça êste grande influência na elaboração das leis. Pode-se, além disso, observar que, constitucionalmente encarregada da aplicação da lei, a administração, prolongamento do govêrno, goza, para realizá-la, de certo poder discricionário, de que se vale oportunamente.

Mas, para as normas regulamentares ou costumeiras, é incontestável aquêle arbitrio. Os regulamentos são feitos pelas autoridades administrativas, isto é, pelos órgãos das administrações públicas, e sabe-se que o poder regulamenter pode exercer-se livremente, desde que não impedido por lei.

A administração tem, enfim, o poder de criar normas de direito por forma extra-regulamentar: são as práticas administrativas; e é certo desde há muito, que, em numerosas matérias, os precedentes e as trađições aủministratives tendem à criação de verdadeiras regras de direito.

Portanto, em virtude da possessão dos direitos de autoridade pública, da prerrogativa de ação própria e de uma dominação incontestável sôbre as normas de direito, ocupam as administrações públicas posição de superioridade muito evidente, em relação aos administrados, comportando-se a respeito dêles de maneira inteiramente diversa daquela dos indivíduos entre si na esfera do direito civil.

Justiça comutativa e Justiça distributiva - Se quisermos distinguir de maneira mais jurídica e mais teórica o direito privado do direito administrativo, poderemos dizer que o direito privado é disciplina impregnada de justiça comutativa, ao passo que o direito administrativo é impregnado de justiça distributiva.

A justiça comutativa, sabe-se, é uma justiça entre partes iguais, estabelecida de grupo para grupo, ou de individuo para indivíduo e sem preocupação de um interêsse superior zo das partes. Os Gregos denominavam diké essa justiça igualitária. 
A justiça distributiva, ao contrário, é aquela que é inerente a um grupo scocial e que, por êsse motivo, tem em grande aprêço os interêsses do grupo; ela implica, em benefício daquêle que a aplica, grande reserva de poder disciplinar, e não se preocupa senão muito pouco com a igualdade entre as partes. De bom grado, denominavam os Gregos thémis a essa forma de justiça.

A formação do direito administrativo explica que êle seja impregnado de justiça distributiva, porque, apesar da extensão do quadro em que se êle aplica, permanece uma disciplina própria de um grupo; o direito administrativo é essencialmente o direito da instituição administrativa.

Esse fato de ser o direito administrativo sobretudo um direito institucional vai ter outra consequiência: é que, muito mais que o direito privado, será êle impregnado de finalidade.

E clássico dizer-se que o direito administrativo é irteiramente dominado pela idéia de utilidade pública e que essa noção, nas suas diversas ramificações, é ao mesmo tempo a razão e a medida dos poderes e dos direitos das autoridades administrativas: ela é quie encontramos como fundamento do processo de expropriaçäo por motivo de utilidade pública, como fundamento co domínio público, que é uma propriedade submetida a um regime especial, por morivo de interessar à utilidade pública; ela é que, igualmente, deve inspirar as medidas de polícia tomadas pelas autoridades administrativas - e a proposição do desvio do poder não é senão um meio inventado peio Conselho de Estado para controlar, no exercício da polícia, a obediência à regra da utilidade pública e do benefício do serviço.

Sem dúvica, na hora presente, assistimos, em direito privado, a um completo movimento dout-inal tendente a demonstrar que o direito civil, também êle, está impregnado de finaliảade (aqui nos

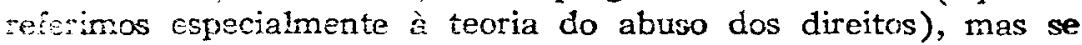
etra direito privado há finalidade, não é isso ainda a utilidade social: nosso direito privaco continuou essencialmente individuaiista, ao gasso que nosso direito administrativo, por intermédio da nocão da utilidade púbica, está em seu conjunto submetido à Gáia do interésse comum.

Parece, poitanio, após êsse rápicio quadro comparativo, termos conciuíco do espírito e das tendências respectivas do direito privado e do direito administrativo, que não existem senão muito poucas reiáçes entre as duas disciplinas e, a priori, parece dificil admitirse cue tentha o direito privado pedido inffuir na formação do cireito administrativo e fornecer-lhe princípios ou regras para resolver problemas juridicos que, à primeira vista, se manifestam com caráté tão particular. 
Entretanto, refletindo-se bem, percebe-se que há boas razōes para se estabelecerem algumas relações entre o direito administrativo e o direito privado.

Antes de tudo, existem principios jurídicos gerais, dominando todos os ramos do direito, e que, com modalidades diferentes, devem ter aplicação tanto em direito administrativo como em direito privado.

Em segundo lugar, convém separar que o direito administrativo não foi elaborado senão tardiamente, em um meio jurídico impregnado de tendências e de tradições civilistas, graças à ação de administradores, de juizes, de membros do Parlamento ou de autores, formados, êles próprios, na escola do direito civil e do direito romano.

Não é, portanto, espantoso que alguns empréstimos tenham sido tomados pelo direito administrativo zo direito privado e que nas irstituições administrativas se encontre boa quantidade de normas ou de princípios civilistas que foram adaptados, transpostos ou mesmo algumas vêzes diretamente utilizados.

A função suplețiva do direito privado - Para definir o processo mediante o qual se operaram êsses empréstimos do direito comum, contentamo-nos geralmente em lembra- que o direito privado deve ser considerado como supletivo em relação às normas administrativas. Não só, porém, nesse sentido de que, em caso de silêncio das regras administrativas, se aplicam literalmente as leis ou códigos do direito privado, mas também no sentido de que o juiz administrativo, quando os problemas que se the apresentam não encontrem atssolutamente solução nos textos administrativos, pode e deve aplicar as regras gerais que as leis civis contêm. Em verdade, os tribunais administrativos e, particularmente, o Conselho de Estado, são muitas vêzes levados a semelhantes empréstimos, para criar, por exemplo, a teoria administrativa da responsabilidade por culpa, as regras dos contratos administrativos, as do processo administrativo, etc. Procedem, nesse caso, a uma adaptação das regras do direito privado, tendo em consideração os caracteres próprios do direito administrativo francês: organização corporativa e institucional das administrações públicas, no caso de responsabilidade por culpa; existência das prerrogativas da ação própria e celeridade da ação administrativa, nos do processo administrativo; continuidade e regularidade no funcionamento dos serviços públicos, no caso dos contratos administrativos. (V. para o quase-contrato a nota de M. Mestre, S. 31, III, 57).

Não se creia, entretanto, que a utilização do direito privado em direito administrativo seja sempre o resultado de ação con- 
ciente e voluntária, nem, sobretudo, que essas transposiçōes se operem sempre de um só golpe, segundo uma espécie de plano preconcebido, no momento $\mathrm{\epsilon m}$ que se apresenta um problema juridico para o qual importa achar uma solução.

Para um grande número de importantes teorias do direito administrativo (função pública, domínio público, delegação), podemos distinguir um processo de transposicão, bastante longo geralmente, no qual colaboram a prática, a doutrina e a jurisprudência e que, pelo desenrolar dos saus episódics, mostra que o direito administrativo e o direito privado se comportam como sistemas autônomas, seguindo cada um sua evolução própria, com influência, porém, do direito administrativo, a qual se manifesta sôbre pontos decterminados por alternativas de atração e de repulsão.

As fases do processo do transposição são geralmente em número de três: transferência pura e simples para o direito administrativo de uma teoria ou de uma regra de direito privado, movimento de reação provocado por uma consciência mais nítida das necessidades ađministrativas, adaptaçōes da regra de dire to privađo fazendo-a experimentar as transposições necessárias.

A teoria do domínio público fornece um primeiro exemplo, não muito conhecido, mas bastante curioso, dessa evolução.

A tese do direito de guarda, segundo a qual as administrações públicas não teriam sôbre as dependências dominicais senão uma sorte de direito de polícia, totalmente diferente do direito de propriedade, não data, como geralmente se crê, de Proudhon; foi suscitada no século XVII, ou mesmo no século XVI, segundo DOMAT ${ }^{1}$ e LOYSEAU, ${ }^{2}$ como uma reação contra a concepção feudal em vigor nos séculos precedentes e segundo a qual as coisas públicas (estradas, rios, etc.) eram possuídas pelos reis oü pelos senhores, conforme as regras da propriedade feudal, isto é, da propriedade privada, não se baseando o uso comum senão na permissão do proprietário.

Essa doutrina do direito de polícia, que teve o grande merecimento de pôr em evidéncia a idéia de utilidade pública, que justifica a cominicalização e que, por êsse motivo, é ainda sustentada por autores tais como M. BERTHÉleMry, ${ }^{3}$ nunca pôde, entretanto, dar explicação satisfatória do procedimento das administrações em relação ao selı domínio, e eis porque foi progressivamente abandonada.

1 Traité sur le comaine public, Livre I, tit. VI, sec. I, $\delta \S 6$ et 8 .

2 Traite des seifneurios, chap. MI, n. ${ }^{\circ} 79$, et chap. $\mathbf{X I}, n{ }^{\circ} 120$.

$312 \mathrm{ed}$, pp. 477 e ss. 
A tese moderna da propriedade dos bens patrimoniais, aceita atualmente pela maioria dos autores e pelo Conselho de Estado," é uma transposição da teoria civilista, operada em consideração ao fato da atribuição das dependências dominicais à utilidade do público ou aos serviços públicos.

As delegações em direito público e a teoria do mandato Outro exemplo, mais típico, talvez, do processo de transposição pode se: tirado da teoria das delegações em direito público.

O problema das delegações nasceu com o Estado e está ligado ao seu desenvolvimento territorial, político e social. Sobrevém um momenta, no organismo político e administrativo, em que as autoridades públicas constituídas já não são suficientes para as tarefas, que se multiplicam; é preciso, para dar vasão aos negócios, ou criar novos magistrados, ou recorrer ao processo da delegaçāo.

As delegações foram numerosas em Roma, conhecidas no antigo direito francês (não queremos, para exemplo delas senão os subdelegados, que, tão frequientemente, operavam em substituição do intendente), são frequientes em direito francês moderna, onde as encontramos seja como delegações entre órgãos constitur cionais (poder outorgado ao Presidente da República para completar a lei por meio de regulamentos de administração pública; poder ao executivo para, em periodo excepcional, expedir decretosleis com a mesma fôrça das leis pròpriamente ditas); seja como delegações entre órgãos administrativos (Delegação do Conselho Geral à Comissão Departamental, delegação feita pelo Prefeito (Maire) nas grandes cidades aos seus diversos adjuntos).

O problema que se apresenta é o da análise jurídica dessa operação: quais são as relações que se estabelecem entre o órgão delegante e o órgão delegado, quais os poderes de que se investe aquêle que foi o objeto da delegação.

Durante muito tempo se analisaram essas diversas operaçōes em delegações de poderes e a discussão era feita sobretudo a propósito do regulamento de administração pública. Via-se nesses atos o resultado de uma delegação do poder legislativo ao Presidente da República e a consequiência que daí se tirava era a impossibilidade de submeter ao contrôle do juiz atos que procediam, assim, de uma delegação legislativa e participavam do caráter intangivel da lei.

4 C. E., 15 jen. 1923, Piccioli, R., p. 44, S. 25, II, 17, J. A., III, 202. 
Essa teoria da delegação do poder era, insiste-se en assinalar, a transferência pura e simples em direito administrativo de uma teoria de direito privacio, a teoria do mandato. Em um como em outro caso, assistia-se a uma delegação de poderes entre o mandante e o mandatário, de tal sorte que o ato realizado pelo delegado tinha exatamente o mesmo caráter que o executado pelo delegante.

Essa teoria foi aceita sem discussão pelos autores e pela jurisprudência até o fim do século XIX. Mas a essa época apareceram, um após cutro, dcis artigos, um de M. EsMeIN em 1894, outro de M. BerthélemY, em 1898, pelos quais foi demonstrado de maneira peremptória que o poder não se pode delegar. Esses autores, estabelecendo a distinção entre os órgãos constituintes e os órgãos da Constituição, mostram que as atribuições de competências e de poderes feitas pela Constituição não podem ser modificadas fora de tempo e que um órgão constituído nenhuma qualidade tinha para delegar a outro órgão poder que the era peculiar.

A consequiência dêsse movimento doutrinal, que se deve ccosiderar como reação muito clara contra a trasladação pura e simples, em direito adininistrativo, de uma teoria civilista, foi que o Conselho de Estado, por um acórdão dito "das Grandes Companhias", datado de 6 de setembro de 1907, raconheceu o caráter administrativo do regulamento de administração pública e a possibilidade de se intentar̆, contra êle, recurso por excesso de poder.

Era admitir a impossibilidade de transferir, pura e simplesmente, ao direito administrativo, a teoria civilista do mandato.

A terceira etapa da evolução: a transposição e a. adaptação da teoria civilista encontra-se assinalada em uma nota do decano Hauriou ao aresto Epoux de Sigalas, datado de 22 de junho de 1928," juntamente com a explicação das relaçóes jurídicas que se estabelecem entre o delegante e o delegado.

A explicação consiste em examinar as delegações que se estabelecem entre as diversas autoridades, não sòmente como delegaçōes de poder, mas como delegações de matérias. A demonstração disso pode ser feita a propósito do regulamento de aciministração pública.

Quando o Parlamento encarrega o chefe do Estado de baixar um regulamento de adminisúração pública para completar uma 
lei, êle the delega certa matéria, certa categoria de negócios, com incumbência de organizá-los nos pormenores. Do fato dessa autorização, que the é dada pelo poder legislativo, tira o executivo a atribuição para completar as disposiçōes que já se encontram na lei e para estabelecer ao lado das normas de direito decretadas pelo Parlamento outras normas de direito que virão justapor-se às primeiras. Mas o Presidente da República, quando elabora com o concurso do Conselho de Estado um regulamento de administração pública, procede com sua competência e seu poder próprio de órgão executivo. A matéria the é delegada, êle a organiza com o seu poder regulamentar.

Essa teoria da delegação de matérias, que já foi aceita por um bom número de autores, ${ }^{6}$ permite explicar, de um lado, que, pelo regulamento de administração pública, o poder executivo tem qualidade para completar a lei e para decretar disposições que serão obrigatórias para os cidadãos, do mesmo modo que a própria lei, e, por outro lado, que o regulamento de administração pública permanece, apesar de tudo, um ato administrativo e, no caso em que seja acoimado ce ilegalidade, isto é, na hipótese em que, em quaisquer das suas disposições, esteja em contradição com a lei que visava completar, será êle passível de anulação pelo Conselho de Estado, da mesma forma que qualquer decisão administrativa.

A importância dessa teoria não é, além disso, restrita ao caso do regulamento de administração pública; tem ela o mesmo valor explicativo para os outros casos de delegações, quer se trate de delegações entre órgãos constitucionais, das quais os decretos-leis são outro exemplo, quer se trate de delegações entre órgãos administrativos, como aquelas feitas pelo Prefeito a seus adjuntos, ou aquelas do Conselho Geral à Comissão Departamental.

Outros exemplos de transposição, ao direito administrativo, das regras e principios do direito privado poderiam ser dados a propósito, por exemplo, da situação jurídica dos funcionários, dos contratos ou dos quase-contratos administrativos.

Quisemos sòmente apontar uma direção na qual algumas pesquisas poderiam ser feitas e notar um processo de elaboração do direito administrativo que até hoje não foi talvez suficientemente pôsto em evidência. 